\title{
CONFLICTOS EN LAS ENCOMIENDAS Y REDUCCIONES DE PULARES Y GUACHIPAS DE LA JURISDICCIÓN DE SALTA: LA PARTICIPACIÓN INDÍGENA EN EL SISTEMA JUDICIAL (FINES DEL SIGLO XVII)*
}

\author{
CONFLICTS IN ENCOMIENDAS AND REDUCTIONS OF PULARES AND \\ GUACHIPAS IN THE JURISDICTION OF SALTA: INDIGENOUS PARTICIPATION \\ IN THE JUDICIAL SYSTEM (LATE 17TH CENTURY) \\ Sergio Facundo Rueda**
}

\begin{abstract}
A partir del análisis de un pleito de 1697, que tuvo como protagonista al protector de naturales junto con unos indios en contra de sus curas doctrineros, el presente artículo pretende analizar la participación indígena en el sistema judicial hacia fines del siglo XVII en la jurisdicción de Salta. Desde una perspectiva microhistórica tomamos como unidad de observación los pueblos de indios reducidos en Pulares y Guachipas para explorar e indagar las relaciones sociales entramadas en el pleito y la forma en que las poblaciones indígenas se han articulado con la justicia. La hipótesis se basa en que dicha participación puede ser entendida como una estrategia de resistencia, adaptación y reproducción social frente al contexto colonial. El estudio de este caso permite observar el descenso demográfico de estos pueblos reducidos, donde los caciques actuaron como defensores y representantes de intereses personales y colectivos.
\end{abstract}

Palabras claves: Protector de naturales, pueblo de indios, curas doctrineros, caciques, Salta.

Following the analysis of a lawsuit of 1967 whose protagonist was the protector of natives with some natives against their doctrinal priests, this article intends to inquire about the participation of the natives within the judicial system at the end of the XVII century in the jurisdiction of Salta. From a micro-historical perspective we take as the unit of observation the reduced peoples of natives in Pulares and Guachipas to explore and investigate the social relations embedded in the lawsuit and the which natives populations have articulated with justice. The hypothesis is base don the fact that said participation can be understood as a strategy of resistance, adaptation and social reproduction in the face of the colonial context. The study of this case allows us to observe the denographic decline of these small towns, where the caciques acted as defenders and representatives of the personal ando collective interests.

Key words: Protector of natives, peoples of natives, doctrinal priests, caciques, Salta.

\section{Introducción}

La formación de los pueblos de indios en el Tucumán colonial tuvo su momento clave a partir de las ordenanzas del oidor Francisco de Alfaro (1612), quien desde la intención de tasar los tributos indígenas promovió la creación de reducciones en una búsqueda de consolidar el dominio colonial (Palomeque 2000). El proceso de conformación de reducciones se vio revitalizado tras la finalización del tercer levantamiento Diaguita-Calchaquí (16591667), junto con la política de desnaturalización llevada a cabo por el gobernador Alonso Mercado y Villacorta, que funcionó como estrategia de dominación y disciplinamiento para desactivar la resistencia indígena (Giudicelli 2018). En la jurisdicción de $\mathrm{Salta}^{1}$, algunas de las poblaciones del valle Calchaquí fueron reducidas en pueblos de indios, conformando las "macrorreducciones" de Pulares y Guachipas, ambas localizadas en el valle de Lerma $^{2}$ e integradas por una multiplicidad de pueblos colindantes entre sí (Castro Olañeta 2018) ${ }^{3}$.

La macrorreducción de Pulares, situada en la boca de entrada de la quebrada de Escoipe (actual Chicoana), estuvo conformada por los pueblos de Pulares, Chicoana, Atapsi, Cachi, Payogasta, Taquigasta, Sicha y Cafayate. Por su parte, el espacio reduccional de Guachipas, ubicado a pocas leguas de Escoipe, se halló compuesto por los pueblos de Animaná, Bombolán, Anguigasta, Pompona, Gualfín y Ampascachi (Castro Olañeta 2007, 2018).

\footnotetext{
* $\quad$ Forma parte del proyecto CIUNSA 2476.

** Facultad de Humanidades, Universidad Nacional de Salta- CIUNSa. Dirección postal: Avenida Bolivia No 5159. CP: 4400. Salta. Argentina. Correo electrónico: facurueda5@gmail.com
} 
El sentido de reducir estos pueblos en el valle de Lerma estuvo orientado a la necesidad de contar con mano de obra indígena mediante la efectivización de las encomiendas. Precisamente en Pulares y Guachipas se habían instalado haciendas y estancias cuyos propietarios y encomenderos estaban dedicados a las actividades agrícolas y ganaderas, como la invernada de ganado mular, orientadas a abastecer los mercados mineros que se desarrollaron en torno a Potosí (González Rodríguez 1982; Mata 2005).

En este marco, los pueblos de indios operaron como un espacio de interacción entre indígenas y agentes españoles, cuyas relaciones giraron en torno a tensiones y conflictos que pueden verse reflejadas en la participación indígena dentro de la justicia colonial.

En el presente artículo analizamos la participación indígena en el sistema judicial a partir de un caso sucedido en los espacios reduccionales de Pulares y Guachipas, hacia fines del siglo XVII. Desde una perspectiva microhistórica, tomamos como unidad de análisis a los pueblos de indios, entendidos como una categoría que presenta como principales atributos la propiedad comunitaria de tierras, un sistema político encabezado por caciques y cabildos indígenas, y la adscripción de los sujetos del pueblo a un sistema tributario (Castro Olañeta 2006). Centramos nuestra observación respecto de estas macrorreducciones para explorar e indagar las relaciones sociales entramadas en el pleito y la forma en que las comunidades indígenas reducidas se han articulado con la justicia (Oyarzábal y Estruch, 2016).

Partimos de la hipótesis de que dichas acciones pueden interpretarse como parte de estrategias individuales y comunales de resistencia, adaptación y reproducción social ${ }^{5}$ en el contexto colonial. Consultamos como fuente principal un pleito que data de 1697 y contiene la denuncia del protector general de naturales, en representación de unos indios, en contra de sus curas doctrineros ${ }^{6}$.

\section{El inicio de un pleito: identificando los agentes en la denuncia}

En febrero de 1697, en la ciudad de Salta el protector de naturales "por defensa de Don Felipe Pacañai, Don Joseph Pallamaz y Don García, caciques y gobernadorez de los Pueblos de Bombolán animana y Casmichango" y "de todos los demás caciques de las reducciones de San Francisco de Ampascache y San Pedro de Pulares"7 (AAS-CCE
1697: 1), presentaba una denuncia en contra de unos curas doctrineros. Los acusaba de maltratar y castigar a los indígenas, de sacar indios para su servicio y de haberlos dado a sus parientes, haciendo lo mismo con las indias casadas y solteras, produciendo la destrucción y "despoblación"8 de los pueblos, como así también de haber llevado algunos tributarios para tropas y amanses de mulas, provocando la pérdida de trigo e impidiéndoles el cumplimiento de la mita y las tasas a sus encomenderos. Dicha petición incluía la solicitud explícita de justicia a base de las ordenanzas reales y las leyes nuevas de recopilación respecto de las competencias y prohibiciones de curas y doctrineros 9 .

Es importante destacar que el protector de naturales era Leonardo Rodrigo Valdéz, natural de los principados de Asturias ${ }^{10}$, vecino encomendero del pueblo de Sicha de nación Calchaquí, reducidos en Pulares, cuya encomienda había sido adquirida en 1670 (Fortuny, 1966). Ocupó los cargos de capitán (1671), alférez real (1671), sargento mayor (1687) maestre de campo (1697), alguacil mayor de la Santa Inquisición (Bonorino, 1997). Al momento de efectuarse la denuncia citada en el documento de 1697 ocupaba el cargo capitular de alcalde ordinario de segundo voto y el de protector general de naturales, designado por el oidor Luján de Vargas en la vista de 1693 a las encomiendas de Salta (AAS-CCE 1697) ${ }^{11}$. Entre sus propiedades se destacaron el potrero de Escoipe y Rosario Viejo, ambas localizadas dentro del valle de Lerma y esta última heredada de su matrimonio con Josefa de Elizondo, prima de uno de los curas denunciados ${ }^{12}$.

Por su parte, los denunciantes fueron don Felipe Pacañai, curaca del pueblo de Bombolán, don Joseph Pallamaz de Animaná y don García, curaca del pueblo de Casmichango. Los pueblos de Bombolán y Animaná estaban reducidos en Guachipas y encomendados al capitán don Juan Abreu y Figueroa, bisnieto del gobernador Gonzalo de Abreu. El pueblo de Casmichango estaba conformado por calchaquíes desnaturalizados, encomendados al capitán Domingo Pérez de Quintana desde 1671 por orden del gobernador Ángel de Peredo.

Junto con la petición estaba la denuncia de un indio llamado Pascual, yerno de don Felipe Pacañai y tributario del pueblo de Bombolán. La presentación estuvo orientada al pedido de justicia por parte del protector, en defensa y por pedido de Pascual por "los azotes y la cuelga en el algarrobo, la trasquila 
del cabello y la quita de un caballo, junto los lomillos, el freno y las espuelas" que le propiciaron los curas doctrineros (AAS-CCE 1697: 4).

Finalmente, los curas acusados eran Pedro Carbajal y Loria $^{13}$ y Simón Díaz Zambrano ${ }^{14}$, ambos emparentados a familias beneméritas y propietarias del valle de Lerma. Al momento de inicio del pleito, cada uno era propietario de las doctrinas de San Pedro de Pulares y la de San Francisco de los Calchaquíes, respectivamente; la primera con jurisdicción de los pueblos reducidos en Pulares, mientras que la segunda a cargo de los pueblos reducidos en Guachipas (Larrouy 1923; Vergara 1923). Las doctrinas que operaron como células de conversión desde un estatus jurídico, expresado en divisiones territoriales, de las que se hallaban insertos un número de indígenas a cargo de un cura doctrinero, quien tenía la misión de adoctrinarlos a cambio de una paga hecha por el encomendero (Acosta 1986; Ávalos 2001).

\section{Reconstruyendo la denuncia: las voces indígenas en el pleito}

Conocer la verdad era la finalidad en los pleitos y es allí en donde el discurso a través de las testificaciones de los sujetos implicados significaba uno de los medios que disponía el juez para resolver el caso (Bixio, 2001). Concentrar la mirada sobre las testificaciones implica prestar atención al análisis del discurso y todo lo que en su interior se puede ocultar. En este sentido, sugestiva resulta la hipótesis de Scott (2000), para quien los discursos dan cuenta de relaciones de poder y estructuras de dominación que se expresan en discursos públicos entendidos como aquellos que circulan en el ámbito de la hegemonía de dominación, y los ocultos que tienen lugar en un público diferente, generalmente asociado a los grupos dominados.

Tomando como guía estos planteos, en el presente apartado nos concentraremos en recuperar las voces indígenas dentro del pleito y dar cuenta parte de ese "discurso oculto". Primeramente, cabe considerar que entre los indígenas que prestaron declaración encontramos a los denunciantes y cuatro caciques que testificaron a favor de Pedro Carbajal y Loria, siendo todos denominados como "ladinos" al comprender el castellano. Las declaraciones fueron tomadas en presencia del intérprete capitán Don Juan de Villagra y Mendoza y del escribano Agustín Vázquez.
En abril el vicario y juez eclesiástico Pedro Chávez de Abreu citó a declarar a los indios denunciantes, preguntándoles: 1) si su cura había sido el causante de la destrucción y despoblación de los pueblos, 2) si el cura había sacado indios para las tropas recuas y amanses de mulas y otros edificios, siendo esto la causa de no pagar la tasa al encomendero ni la mita, como así también el maltrato y 3) si se perdió el poco trigo y hubo tasa de mita.

Don Felipe Pacañai, dijo "que de ninguna manera a dho ni asegurado a su protector el que dho su cura (Díaz Zambrano) a sido causa de la destruccion y despoblacion" (AAS-CCE 1697: 5), y que una vez había recibido azotes por parte del doctrinero por haberse opuesto a que llevase indios de la reducción. Asimismo, declaró que el cura no había sacado indios para los amanses de mulas, y que habían enterado la mita por completa y que no pagaba al encomendero tasa alguna.

Don García, si bien no responsabilizaba a los curas de la destrucción de los pueblos, sí denunciaba que Zambrano le había quitado una "china soltera" y que se había servido del padre de la misma, Antonio, carpintero, no pagándole por los servicios. También afirmaba haber recibido azotes por haber escondido a un muchacho llamado Agustín, del mismo pueblo. Respecto de la segunda pregunta expresó que los curas no tenían tropas de mulas pero que en una ocasión uno de ellos había mandado a un indio llamado "Perucho" hacia el Potosí con unas cargas de yerba. De la tercera pregunta, afirmó que la mita de la plaza había sido enterada y que la tasa a su encomendero se había realizado en servicio personal.

Don Pallamaz denunció que el cura le había quitado tres indias solteras y dos indios, llevándolos a trabajar a la ciudad, pero a pesar de ello no había producido la destrucción del pueblo. En referencia a las tropas de mula testificó que el cura no había sacado indios para tales fines. Por último, dijo haber enterado la mita y que los "encomendero tienen sus chacras lo mas de los indios [...] despoblando las reducciones" (AAS-CCE 1697: 6).

En relación con la denuncia realizada por Pascual, este afirmó haberse quejado ante su protector natural alegando que el maestro Díaz Zambrano "lo mando a desnudar y colgado a un algarrobo le dio muchos asotes y le despunto el cabello y le embargo un cavallo con sus lomillos un chuce espuelas y un freno de mala de madera" y que hasta el momento no se lo había devuelto (AAS-CCE 1697: 6). 
Si constatamos las declaraciones de estos caciques junto con la denuncia presentada por el protector de naturales encontramos que existe cierta discrepancia. En la presentación inicial el protector acusa a Díaz Zambrano y a Carbajal y Loria, pero resulta que en las testificaciones los curacas y Pascual solo hacen referencia al primero, sin hacer mención del otro cura. Seguidamente se puede observar cómo los indios confirman los castigos recibidos y la saca de algunos indios para la realización de algunas tareas, pero ninguno afirma haber dicho que los curas sean los responsables de la destrucción y despoblamiento de los pueblos. En este sentido, resulta interesante la declaración de Pallamaz, al decir que los encomenderos cuentan con indios en sus chacras, y de don García, quien afirmaba pagar la tasa de tributo en servicio personal.

Es importante señalar que, en su defensa, ambos curas pusieron en duda la legitimidad de los denunciantes. Exclamaron que la denuncia presentada eran calumnias en contra de ellos y que el protector había involucrado a los caciques de Guachipas y Pulares, otorgando títulos de caciques y gobernadores que eran inexistentes en la jurisdicción de Salta, afirmando que solo Felipe Pacañai era cacique, que Pallamaz ostentaba el título de alcalde y don García era tributario.

Ahora bien, durante el proceso contamos con el testimonio de cuatro caciques de los pueblos reducidos en Pulares, quienes testificaron a favor de Carbajal y Loria. Entre ellos se destacaron don Francisco del pueblo de Atapsi ${ }^{15}$, don Marcos Silca del pueblo grande de Pulares ${ }^{16}$, don Pablo Hatin del pueblo de Cafayate ${ }^{17}$ y don Francisco Chumbicha del pueblo de Sicha, con la particularidad de que este último formaba parte de la encomienda del protector de naturales ${ }^{18}$.

Los discursos de los caciques fueron similares entre sí, declarando que ninguno de ellos había presentado una queja ante el protector de naturales y que recibían un buen trato por parte de Carbajal y Loria. Acerca de la mita de la plaza, afirmaron que había sido repartida por el alcalde ordinario Leonardo Rodrigo Valdez, siendo enterada en tiempo y forma durante enero y febrero. Ahora bien, los mismos expresaron que los encomenderos sacaban indios de las reducciones y doctrinas y los tenían dentro de sus chacras y haciendas. Por último, en referencia a la tributación dijeron "no pagar los indios tributarios a sus encomenderos en plata ni generos sino en servicio personal como es nottorio y puesto en usso y costumbre en esta dha ciudad" (AAS-CCE 1697: 31).

Los testimonios de estos últimos caciques junto con el de los denunciantes permiten deslumbrar ciertas cuestiones. La primera se refiere a la estrategia de la denuncia presentada por el protector de naturales, al acusar a los curas de la destrucción y despoblación de los pueblos, como así también al involucrar a los caciques de las reducciones de Guachipas y Pulares. Hemos visto cómo los testimonios señalan que los encomenderos acostumbraban a sacar los indios de sus pueblos para asentarlos dentro de sus propiedades.

La segunda cuestión nos lleva a considerar que los indígenas conmutaban las obligaciones tributarias por medio del servicio personal, práctica que a pesar de estar prohibida por las ordenanzas de Alfaro (1612) continuaba persistiendo. De estos aspectos profundizaremos luego.

Una tercera cuestión refiere a que el despoblamiento de los pueblos de indios no puede reducirse solo al accionar de los curas, así como expresa la denuncia presentada por el protector. El problema del despoblamiento resulta más complejo al observar en él un foco de tensión entre los intereses de los encomenderos y los curas implicados.

$\mathrm{Al}$ final del pleito ambos curas fueron absueltos. Mucho tuvieron que ver las testificaciones de los caciques, pero lo que orientó el rumbo de la causa fue la situación de Pascual. El cura Díaz Zambrano había castigado ${ }^{19}$ a este tributario por haber querido matar a su antecesor, el maestro Pedro Fernández. En referencia a la trasquila a Pascual dijo no haberla hecho y acusó al protector de naturales de inducir al indio para la denuncia. Resulta que, al presentarse a declarar, Pascual asistió con el "cabello recogido atrás hecho un obillo entretegido con trensas con tal dismilo que a no aberle a vmd dado abisso" (AASCCE 1697: 33), según lo afirmado por el sargento mayor Antonio Gutiérrez Maldonado, el alférez Pedro Nolasco Díaz de Pastrana y el presbítero Francisco Fernández de Chaves. Estos testigos mencionaron que, estando reunidos en la casa del acalde provincial de la ciudad de Salta, se acercó un indio al que luego reconocieron como Pascual. El sargento mayor Antonio Gutiérrez Maldonado relata que:

entro a dicha casa un indio a quien dijo este declarante no conocer y luego que le vieron las personas referidas dijeron 
riendoce y exagerándolo este es el indio que le imputaron al Mro Simon Dies que abia trasquilado notando todos dichos como tambien este declarante tener el cabello largo y trensado con una trensa q le daba hasta la espalda y que asi mesmo por esto decir a varias personas q el dicho indio se abia ydo a querellar ante su merced llevando en la oración recogido y tado el cabello con grande dicimulo (AAS-CCE 1697: 34)

De esta manera el caso se resolvió a partir de la falsedad de la "trasquila del cabello", siendo certificado por el escribano y así, Pedro Chaves de Abreu, en agosto de 1697, declaró absuelto a los curas denunciados en esta causa. Por cuestiones ligadas a la conservación del documento no sabemos si el protector de naturales y los denunciantes recibieron alguna condena, $\tan$ solo podemos afirmar que los curas denunciados solicitaron la excomunión y una pena pecuniaria contra el protector Rodrigo Valdez.

\section{Encomenderos y curas: un conflicto de elite}

La relación del derecho y la práctica judicial durante la Colonia puede entenderse como una práctica política en la que intervinieron una diversidad de agentes y un universo de relaciones (Bixio 2001). En este sentido, los conflictos judiciales significaron una vía de expresión de relaciones de poder, donde es posible identificar el grado de tensión y conflictividad entre los involucrados. En referencia al caso abordado, nos preguntamos ¿qué pudo haber incentivado al protector de naturales Valdez a presentar la denuncia en contra de Carbajal y Loria y Díaz Zambrano?

El pleito permite observar que la relación entre el protector y los curas se hallaba atravesada por intereses políticos y económicos, algo muy frecuente dentro de la jurisdicción del Tucumán colonial. En el caso analizado, claramente el foco de tensión se encontraba en la puja por el control de los pueblos de indios reducidos en Pulares y Guachipas.

Hemos visto que Valdez se desempeñó como protector general de naturales por designación del oidor Luján de Vargas, siendo dicho cargo un espacio para pugnar por intereses personales y controlar la mano de obra indígena. Es admisible señalar que a la vez que se desempeñó como protector ostentó otros cargos capitulares como el de alcalde ordinario llegando a tener injerencia en el Cabildo, lo que le había permitido administrar el reparto de mita, tal como lo dieron a saber los testigos; entre ellos el capitán Alonso Ruiz de los Llanos, que al testificar por Carbajal y Loria dijo: "el año pasado de noventa y seis de mes de diciembre le dio comsiion por escrito a este decía como alcalde hordinario q era alferes real de esta dha ciudad Leonardo Rordrigo Valdes para que fuese a la Doctrina despues sacace la mita para los repartimentos" (AAS-CCE, 1697: 35).

Partiendo de esta información, no sería extraño pensar que Valdez, desde su posición de encomendero, haya buscado lograr un control efectivo de los indígenas reducidos, sobre todo si consideramos la necesidad de mano de obra al estar dedicado al negocio de la invernada de ganado y la producción de trigo, ya que en 1696 lo encontramos negociando con el sargento mayor Joseph Castellanos por la venta de unas fanegas de trigo ${ }^{20}$.

Retomando la relación con los curas, sabemos que estos formaban parte de la elite local al estar emparentados con otras familias encomenderas y propietarias en el valle de Lerma. En este marco los curas operaban en los circuitos comerciales del mercado colonial, sirviéndose para ello de algunos indígenas que habían sacado de los pueblos, atentando contra los intereses del sector encomendero.

El pleito trabajado da cuenta de que uno de los problemas que atravesaban los pueblos de indios era su "despoblamiento". La descripción de los curatos remitida por el vicario Pedro Chávez de Abreu en 1692 permite reconstruir esta situación, donde el mismo Carbajal y Loria denunciaba que la doctrina de San Pedro de Pulares se encontraba "casi yerma y despoblada y no haber podido poner remedio a ello por tener los encomenderos autoridad propia en sus chacras" (Larrouy 1923: 404). En cuanto a la doctrina de San Francisco de Calchaquíes, el maestro Pedro Fernández de Chaves, quien había sido agredido por Pascual, expresaba que los pueblos de indios estaban "despoblados y disipados y fuera de sus reducciones y los yndios con sus mujeres e hijos sujetos a servicio personal" y que la desolación debió a "los fletes y conduciones de ganados que se llevan a los reynos del Perú" (Larrouy 1923: 406). Esta misma situación de los pueblos de indios del Tucumán había sido denunciada por el obispo Ulloa en 1682, derivando en la realización de la visita del oidor Luján de Vargas entre 1692 y 1694 sobre dicha gobernación, y donde los encomenderos habían sido multados por el incumplimiento de las legislaciones vigentes ${ }^{21}$. De esta forma los clérigos 
responsabilizaban a los encomenderos de la situación de los pueblos de indios, al trasladar a los indígenas dentro de sus propiedades y al ocuparlos en largos viajes orientados al Perú, cuyas acusaciones se ven invertidas en la denuncia presentada por el protector de naturales.

Por último, en el conflicto que involucró a Valdez y a los curas doctrineros, se hicieron presente filiaciones y redes de influencia que catalizaron las tensiones entre los mismos, dando muestra de una elite que se presume heterogénea. Valdez estaba casado en primeras nupcias con Juana de Elizondo, hija de Josefa Díaz Zambrano y el capitán Félix Elizondo, y prima hermana de Simón Díaz Zambrano. Los Díaz Zambrano fueron una familia con grandes propiedades en el Valle de Lerma y emparentados con los Elizondo, quienes tenían las encomiendas de Pulares y un tercio del pueblo de Sicha (el otro tercio le correspondía a Valdez). La relación de Valdez con estas familias parece haber sido buena, siendo una muestra de ello cuando su suegra Josefa Díaz Zambrano lo designó tenedor de bienes y tutor de sus hijos menores, pero esta relación podría haber cambiado una vez que tuvo que entregar parte de los mismos a su cuñado José Zambrano en $1689^{22}$.

Por su parte Carbajal y Loria se quejaba al decir que Valdez era "íntimo amigo y confidente" del vicario juez eclesiástico Cosme del Campo Rossa, y que había aprovechado esa situación para presentar la denuncia. Luego sabemos que, si bien la querella fue recibida por Cosme, quien dio curso y finalidad al pleito fue el maestro Pedro Chaves de Abreu, también juez y vicario eclesiástico de la ciudad de Salta.

\section{La participación indígena en el pleito de $\mathbf{1 6 9 7}$ y la situación de los pueblos de indios}

En este último apartado nos concentraremos en el sentido de la participación de los indígenas imbricados en el pleito. La sociedad colonial se ha caracterizado por presentar sus contradicciones, habilitando intersticios que significaron un margen de maniobra en donde indígenas podían tener acceso a la justicia, constituyéndose de esta manera en un espacio para emprender resistencia y adaptación, y lograr una reproducción social comunitaria dentro de un contexto totalmente desfavorable (Castro Olañeta 2004; García 2018). Acerca de este punto Palomeque (2000) ha planteado que la preservación de la sociedad indígena dependía de la capacidad de cada pueblo de hacer cumplir las bases legales que lo protegían.

La participación de los indígenas en el pleito analizado dio cuenta de que tanto los caciques como Pascual habrían tenido conocimiento de la existencia de un marco legal que los amparaba ante el maltrato de algún agente colonial, siendo esto un impulso para presentar la queja ante el protector de naturales. A su vez, esta situación también habilitó un espacio para la negociación y así lo deja entrever Pascual al mentir, inducido por el protector, respecto de la "trasquila del cabello", pudiéndose interpretar esta actitud como resistencia ante las relaciones conflictivas que mantenía con el cura doctrinero Díaz Zambrano.

Por su parte, los caciques denunciantes, a pesar que los curas pusieron en duda su legitimidad al remarcar que los títulos de gobernadores y alcalde habían sido impartidos por el protector, operaron como lo que Oyarzábal y Estruch (2016) han llamado "actores intermedios", al actuar como mediadores entre los pueblos que representaban y el sistema judicial. De la misma manera, los testimonios de los caciques presentados por Carbajal y Loria, a pesar de estar mediados por agentes de la cultura peninsular (Oyarzábal, 2016), encontraron en esta situación una posibilidad para dar cuenta de la situación de los pueblos de indios, dándonos apertura para identificar problemas referidos a la situación demográfica, la tributación y a la tierra comunal.

Tanto las declaraciones de los indígenas como las de los curas refirieron a la situación de "despoblación de los pueblos". Al analizar el sentido de esta expresión sostenemos que refiere un descenso demográfico en la cantidad de indios tributarios, y en consecuencia un proceso de pérdida de las tierras comunales. Si comparamos la evolución demográfica de las encomiendas de Salta entre el padrón de 1673 ordenado por el gobernador Peredo (Ravignani 1932) y los datos que arrojan las encomiendas registradas por Luján de Vargas en 1693 (Castro Olañeta, 2017; Doucet 1980; Farberman y Boixadós, 2006), notamos hacia fines del siglo XVII un descenso poblacional de más del 50\% en las reducciones. Entre las principales causas de esta baja demográfica es posible considerar las exigencias excesivas de trabajo, el traslado indígena hacia otros parajes, sea por voluntad propia o de manera compulsiva $^{23}$, y una tendencia en la que los indios 
de encomienda iban residiendo en las tierras de sus encomenderos (Castro Olañeta 2018; Rodríguez González 1982).

El traslado hacia las propiedades de los encomenderos es una realidad que se presentó de manera compleja. Para comprender esta dinámica es necesario tener en cuenta que las reducciones de pueblos de indios se habían establecido en el valle de Lerma como parte de una estrategia de "disciplinamiento" (Giudicelli, 2018) para efectivizar las encomiendas ante la demanda de mano de obra de las haciendas y estancias. Al igual que las declaraciones presentadas en el pleito, la visita de Luján de Varga de 1693 confirma que el servicio personal persistía como la principal forma de tributación. En referencia a ello, Lorandi (1988) planteó que su persistencia en el Tucumán colonial había sido uno de los principales causantes que derivó en la desestructuración de las comunidades indígenas. Aunque podemos mencionar al servicio personal como una de las causas que provocó la disminución demográfica en los pueblos de indios, también existe la posibilidad de que algunos traslados se realizaron como parte de una estrategia de supervivencia adoptada ante la debilidad de la propiedad comunal, lo que también no quiere decir que las mismas se hallan abandonado por completo (Noli 2012).

Si bien no pretendemos explayarnos acerca del problema de la tierra, resaltamos que las propiedades comunales de los pueblos de indios tuvieron importancia en la medida que debían permitir la subsistencia comunitaria. Estas, en el caso de la jurisdicción de Salta, experimentaron un proceso de disputa y despojo por parte de los encomenderos y clérigos. De esta forma, los intereses por la tierra fueron otro foco de conflictos entre indígenas y agentes coloniales que derivaron en la participación indígena en el ámbito judicial, así como sucedió en los litigios que involucraron a las parcialidades de Pulares y Bombolán en contra de sus encomenderos (Mata 2005).

Otro ejemplo de participación indígena en el sistema jurídico colonial lo encontramos en el cacique del pueblo de Sicha (encomienda de Leonardo Rodrigo Valdez), don Francisco Chumbicha, quien había atestiguado a favor de Carbajal y Loria. Durante la visita de Luján de Vargas había aprovechado la oportunidad para solicitar que "mande dar tierras comodas [...] y [...] poner dicho mi pueblo en la estancia de mi encomendero mandándole me señale tierras y agua [...]" (Castro Olañeta, 2017: 599-600). Sucedía que las tierras de su pueblo eran de mala calidad, sumado al agravante de que se encontraban cercadas a dos o tres cuadras de distancia por los pueblos de Atapsi, Chicoana, Chicoana y Tilian, y rodeadas a pocas leguas de las estancias del capitán Fernando Arias, Diego Herrera y de los padres de la Compañía de Jesús, lo que les impedía cultivar la tierra y criar ganado. Así, se estableció una negociación entre el pueblo de Sicha y su encomendero, cuando este último mostró buena predisposición para otorgarles tierras dentro de su estancia, contando con la autorización del visitador.

De esta manera observamos que a partir de las lógicas propias del sistema de dominación colonial los pueblos de indios reducidos en Pulares y Guachipas utilizaron la justicia como un medio para resistir y lograr la persistencia y reproducción social. Ante esto, los caciques cumplieron un rol fundamental dentro de las reducciones, al operar como defensores $\mathrm{y}$ representantes de intereses personales y colectivos del pueblo, frente a las posibilidades que ofrecía el contexto colonial (Sica 2009).

\section{Consideraciones finales}

Son múltiples las investigaciones que han dado cuenta de la potencialidad de los expedientes judiciales como fuentes para recuperar la agencia indígena, a pesar de los filtros culturales que las atraviesan. Por este motivo, en el presente artículo recurrimos a un pleito que involucró a indígenas, encomenderos y clérigos, con el desafío de analizar la participación en el sistema judicial de los pueblos reducidos en Pulares y Guachipas hacia fines del siglo XVII, dentro de la jurisdicción de Salta.

Estas reducciones que se caracterizaron por ser multiétnicas, permitieron un juego de interacciones entre indígenas y agentes coloniales que se presentaron de manera conflictiva. En el marco de dicha conflictividad se entretejieron una trama de "relaciones de poder" (Foucault 1988) que ubicaban a los indios desnaturalizados y reducidos en un estatus de inferioridad, llevándolos a desplegar diversas estrategias enmarcadas en una lógica que Stern (1987) llamó "adaptación en resistencia". Entre estas estrategias, el acceso a la justicia se presentó como una posibilidad para lograr la reproducción social en un contexto que les era desfavorable. 
El pleito analizado dejó entrever una elite heterogénea con diversos intereses y en la que también existían tensiones, como fue el caso del protector de naturales (y encomendero) y los curas doctrineros. De estas relaciones tensas, los caciques denunciantes y un indio tributario encontraron un intersticio para hacer "público" un discurso que se hallaba "oculto" por la misma dominación colonial (Scott 2000). Sus declaraciones junto con las testificaciones prestadas por los otros caciques, nos acercaron a observar la situación de los pueblos de indios de Pulares y Guachipas hacia fines del siglo XVII, los que habían experimentado una baja demográfica a causa del servicio personal, la pérdida de las tierras comunales y la presión ejercida por los agentes coloniales. A pesar de esta situación, los pueblos desde la figura de los líderes étnicos desplegaron acciones que le permitieran resistir y adaptarse, siendo la participación de la justicia uno de los medios para lograrlo.
Desde este trabajo esperamos contribuir y alentar a próximas investigaciones que permitan recuperar la historicidad de los pueblos de indios en la jurisdicción de Salta y que, desde una perspectiva regional, permita comparar con las dinámicas de los pueblos de indios de las demás jurisdicciones que integraron la gobernación del Tucumán.

\section{Agradecimientos}

Se agradece el acompañamiento realizado por Telma Chaile, Cecilia Castellanos y Osvaldo Gerés, como así también los comentarios de Silvia Palomeque, Laura Quiroga y el de los evaluadores externos. Una versión preliminar ha sido presentada al XX Congreso Nacional de Arqueología Argentina. Este trabajo es producto de las becas de investigación otorgadas por el CIUNSa y el Consejo Interuniversitario Nacional.

\section{Referencias Citadas}

Acosta, A.

1986 "Extirpación de Idolatrías en el Perú. A propósito de Cultura Andina y represión". Revista YACHAYRUNA N ${ }^{\circ} 2$, Salta.

Ávalos, D.

2001 La guerra por las almas. El proyecto de evangelización Jesuita en el Tucumán temprano. Siglo XVII. Centro Educativo de San Lorenzo, Salta.

Bixio, B.

2001 Derecho, justicia y población indígena (Córdoba del Tucumán, siglo XVII). Ponencia presentada VIII Jornadas Interescuelas y Departamentos, Salta.

Bonorino, J.

1997 "Salta. Primeras familias de la colonia". Genealogía. Revista del Instituto argentino de ciencias genealógicas. $\mathrm{N}^{\circ}$ 28: 85-290.

Castro Olañeta, I.

2004 "Coyuntura, adaptación y resistencia: actores indígenas y justicia colonial. La participación de los indios del pueblo de Quilino en el espacio de la justicia (Córdoba, 1620)". Cuadernos de historia. Serie Economía y Sociedad $\mathrm{N}^{\circ} 6$ : 71-100, Córdoba.

Castro Olañeta, I.

2006 "Pueblos de indios en el espacio del Tucumán colonial". En Historia Regional. Estudios de casos y reflexiones teóricas, editado por S. Mata de López y N. Areces, pp. 37-49. EDIUNSa, Salta.

Castro Olañeta, I.

2007 Indios encomendados, indios registrados, indios omitidos por el visitador Luján de Vargas. Salta, Gobernación del Tucumán, siglo XVII. Ponencia presentada en XI Jornadas Interescuelas, Universidad Nacional de Tucumán.
Castro Olañeta, I.

2017 La visita del oidor Antonio Martínez Luján de Vargas a las encomiendas de Catamarca, Santiago del Estero y Salta. Gobernación del Tucumán, 1693-1694. Ferreyra Editor, Córdoba.

Castro Olañeta, I.

2018 "Las encomiendas de Salta (Gobernación del Tucumán, siglo XVII)". Andes vol, 2: 1-41, Salta.

Doucet, G.

1980 Introducción al estudio de la visita del oidor don Antonio Martínez Luján de Vargas en las encomiendas de indios del Tucumán. Buenos Aires.

Doucet, G.

1984 "Un Feudo Salteño. La encomienda de Pulares y Tonocotés de los Diez Gómez e Isasmendi”. Publicaciones del Instituto de Estudios Iberoamericanos. Vol. II/IV, UBA.

Farberman, J. y Boixadós, R.

2006 "Sociedades indígenas y encomienda en el Tucumán colonial. Un análisis comparado de la visita de Luján de Vargas". Revista de Indias, 66 (238): 601-628.

Figueroa, M.

2003 Apuntes históricos. Salta en los siglos XVI-XVII. Universidad Católica de Salta, Salta.

Fortuny, P.

1966 Nueva historia del norte argentino: descubrimiento y conquista. Ediciones Theoría.

Foucault, M.

1988 "El sujeto y el poder". Revista mexicana de sociología, $50(3), 3-20$.

García, M.

2018 "Buscando las voces nativas en la justicia colonial: Las autoridades de Malfines y Andalgalas y su reproduccón 
comunitaria (La Rioja, 1674-1693)”. ANDES, vol. 2, No 29, 1-39.

Giudicelli, C.

2007 "Encasillar la frontera. Clasificaciones coloniales y disciplinamiento del espacio en el área diaguito-calchaquí (S. XVI-XVII)". Anuario IEHS No 22: 161-212, Tandil.

Giudicelli, C.

2013 "Hablar la lengua del enemigo: la soledad del misionero en tierras Calchaquíes". En Dossier Misiones en Iberoamérica: dimensiones políticas y relgiosas. Revista Tempo vol. 19 No 35 Niterói,

Giudicelli, C.

2018 "Disciplinar el espacio, territorializar la obediencia. Las políticas de reducción y desnaturalización de los diaguitas-calchaquíes (siglo XVII)". Chungara, Revista de Antropología Chilena 50, № 1, 133-144.

González Rodríguez, A.

1982 "Notas sobre el traslado de los indígenas en la jurisdicción de Salta". Temas americanistas $N^{\circ}$ 1: 49-62.

Larrouy, P.A.

1923 Documentos del Archivo de Indias para la Historia del Tucumán. Tomo I. Imprenta Privat, Tolosa.

Lorandi A.M.y Boixadós R.

2009 "Sobre clasificaciones y descalificaciones. Una revisión crítica de Etnohistoria de los valles Calchaquíes, veinte años después". Anuario del IEHS No 24: 15-38.

Lorandi, A.M.

1988 "El servicio personal como agente de desestructuración del Tucumán colonial". Revista Andina 6: 135-173, Cusco. Lorandi, A.M.

1997 "Introducción. Etnohistoria del Área Andina Meridonial". En El Tucuman Colonial y Charcas, vol. 2, editado por A.M. Lorandi, pp: 15-71. UBA, Buenos Aires.

Mata, S.

2005 Tierra y poder en Salta. El noroeste argentino en vísperas de la independencia. CEPHIA, Salta.

Noli, E.

2009 "Mestizajes, identidad y oficio: San Miguel de Tucumán, siglo XVII". En J. Farberman y S. Ratto, Historias mestizas en el Tucumán colonial y las pampas (siglos XVII-XIX). Editorial Biblos.

Oyarzábal, M. C.

2016 La palabra de los "naturales" en la justicia. Posibilidades y limitaciones en el análisis de la documentacion judicial referida a indígenas (Jujuy, siglo XVII). Universidad Nacional de la Plata. Facultad de Humanidades y Ciencias de la Educación, 2da Época, No 43.
Oyarzábal, M. C. y Estruch, D.

2016 "Indígenas y archivos. Entre el acervo documental y las herramientas metodológicas. El caso de Jujuy Colonial". Revista Historia y Justicia. No 7 Santiago de Chile, 95-121.

Palomeque, S.

2000 "El mundo indígena. Siglos XVII-XVIII". En Nueva Historia Argentina Tomo II, editado por E. Tándeter, pp. 87143. Sudamericana, Buenos Aires.

Quintián, I.

2008 "Articulación política y etnogénesis en los valles calcahquíes. Los pulares durante los siglos XVII y XVIII". Andes $\mathrm{N}^{\circ}$ 19: 299-326.

Quiroga, L., Alvarado, A y Hopkins Cardozo, M.

2018 "Pulares: entre la guerra y la encomienda en las tierras altas del Tucumán colonial, Virreinato del Perú (1577-1630)". Andes $\mathrm{N}^{\circ}$ 29: 1-27.

Ravignani, E.

1932 La población indígena de las regiones del Río de la Plata y Tucumán en la segunda mitad del siglo XVII. $X X V^{\circ}$ Congreso Internacional de Americanistas. Separata de las Actas. Tomo II, pp. 287-305. Universidad Nacional de la Plata, La Plata.

Salazar, J. y Berberián, E.

2015 "Introducción. Algunos apuntes sobre enfoques arqueológicos de la reproducción social”. En Condiciones de posibilidad de la reproducción social en sociedades prehispánicas y coloniales tempranas en las Sierras Pampeanas (República Argentina), editado por J. Salazar, pp. 1-14. Centro de Estudios Históricos Prof. Carlos Segretti. Córdoba Scott, J.

2000 Los dominados y el arte de la resistencia. Ediciones Era, México.

Sica, G.

2009 "Transformaciones y formas de legitimación en la autoridad de los caciques coloniales de Jujuy. Siglo XVII". Revista Memoria Americana 17: 33-59. Buenos Aires.

Stern, S.

1987 "Introducción". En resistencia, rebelión y conciencia campesina en los Andes. Siglos XVII al XX. Editado por S. Stern, pp. 25-41. Instituto de Estudios Peruanos, Perú.

Vergara, $\mathrm{M}$.

1962 Compendio de la Historia del Milagro de Salta. Imprenta de la Provincia de Salta

Vergara, M.

1963 Sinopsis de la Historia Colonial de Pulares y Chicoana. Ed Radio Güemes, Salta.

Wilde, G.

2009 Religión y poder en las misiones guaraníes. San Benito, Buenos Aires.

\section{Notas}

1 Las producciones en torno a los pueblos de indios para la jurisdicción de Salta son escasas. Contamos con las investigaciones de Doucet (1980), pionero en el análisis de la visita de Luján de Vargas y las encomiendas del Tucumán; Sara Mata (2005) en su tesis doctoral "Tierra y poder"; y las producciones de Isabel Castro Olañeta $(2007,2017,2018)$ quien ha realizado una historización de las encomiendas de dicha jurisdicción.
2 Tanto el valle de Lerma como el Calchaquí están localizados en la actual provincia de Salta, Argentina.

3 Hacemos uso del término de "macrorreducciones" a partir de la propuesta de Castro Olañeta (2018). La autora plantea que luego de las desnaturalizaciones del valle Calchaquí, en la jurisdicción de Salta, se conformaron dos grandes espacios reduccionales en Pulares y Guachipas (actual valle de Lerma), en donde se establecieron conjuntos de 
pueblos de indios colindantes entre sí y encomendados a diferentes vecinos.

4 Para aproximarnos a la diversidad étnica que integraba el valle Calchaquí en momentos previos a la conquista se recomienda ver Lorandi (1997). Es importante aclarar que la cuestión "Pulares" ha sido objeto de debate dentro de la historiografía Andina, siendo su identificación étnica uno de los puntos de discusión. Ver los trabajos de Giudicelli (2007, 2013), Lorandi y Boixadós (2009), Quintián (2008) y Quiroga et al. (2018).

5 Entendemos a la reproducción social como el conjunto de acciones y prácticas, individuales o colectivas, empleadas por los indígenas, para preservar y reproducir su cultura y comunidad (García 2018; Salazar y Berberián 2015).

6 Archivo del Arzobispado de Salta (en adelante AAS) -Causas Criminales Eclesiásticas- Carpeta pastoral aborigen $\mathrm{N}^{\circ}$ 5, 1697 (en adelante AAS-CCE 1697).

7 Si bien en el documento se hace mención a las reducciones de San Francisco de Ampascache y de San Pedro de Pulares, estas expresiones aluden a Guachipas y Pulares, respectivamente.

8 El término "despoblación" es empleado constantemente a lo largo del pleito. En los próximos apartados procederemos a analizar su significado.

9 Recopilación de Leyes de los Reinos de las Indias Tomo I, Títulos XIII, XIV y XV. Considerar las disposiciones acerca del "buen tratamiento de los indios" en el Tomo VI, Título X.

10 Archivos y Bibliotecas Históricos de Salta (en adelante ABHS), Fondo Protocolos Notariales, Carpeta 3, Protocolo 43, folio 37., fecha 22-10-1705.

11 El protector general de naturales tenía la función de defender a los indios ante los abusos cometidos, haciendo cumplir lo que estaba establecido por las leyes protectoras de indígenas (Figueroa 2003: 107).

12 ABHS, Juzgado de $1^{\circ}$ instancia, Carpeta $\mathrm{N}^{\circ} 1$.

13 Nacido en Salta en 1658, hijo del matrimonio del capitán Francisco Carbajal y Ana Diez de Loria, realizó sus estudios superiores en Córdoba. Fondo Documental Monseñor Pablo Cabrera. Ex Instituto de Estudios Americanistas, Inventario 02898, año 1682.
14 Nacido en Salta en 1664, hijo de Melchor Diez de Zambrano y María de los Ríos Elizondo, nació en 1665. Murió en 1742 como párroco de San Juan de la Frontera, siendo una de las figuras partícipes de la institucionalización al culto del Milagro salteño (Vergara, 1963).

15 Indios de nación calchaquí reducidos en Pulares, encomienda de Joceph Escobar de Castellanos (Olañeta 2017: 572).

16 Curaca de indios calchaquíes reducidos en Pulares, encomienda del capitán Bernardo Vélez, alcalde ordinario en 1693 (Olañeta 2017: 603).

17 Indios de nación calchaquí reducidos en Pulares, encomienda de Pedro Díaz (Olañeta, 2017: 635).

18 Indios de nación calchaquí reducidos en Pulares, encomienda de Leonardo Rodrigo Valdez (Olañeta 2017: 597).

19 Wilde (2009) remarca que los castigos como los azotes respondieron a una concepción cultural europea marcada por la humillación aplicada en las reglas de los religiosos y tal es así que en este caso operó como medida de disciplinamiento.

20 ABHS, Protocolos Notariales, Protocolo 63, Año 1705, Escribano Pérez del Hoyo, Diego.

21 Esta visita ha sido objeto de indagación en la historiografía colonial. Para el estudio de la jurisdicción de Salta es pertinente considerar las investigaciones en torno a la visita de Luján de Vargas, de Gastón Doucet (1980, 1984), Isabel Castro Olañeta $(2007,2017,2018)$ y el trabajo síntesis en clave comparada de Judith Farberman y Roxana Boixadós (2006).

22 AHPS, Juzgado de $1^{\circ}$ instancia, Carpeta $\mathrm{N}^{\circ} 1$.

23 Recordemos que muchos indígenas eran empleados para arrear las tropas de ganado mular que se dirigían a los complejos mineros potosinos, y a veces podían darse los casos que estos optaban por no regresar a su pueblo (Rodríguez González 1982). También es posible considerar que los traslados se realizaban de manera compulsiva, como fue el caso de la encomienda de Pulares y Tonocotés, donde el encomendero Isasmendi había trasladado a los tributarios hacia la hacienda de Molinos localizada en el Valle Calchaquí (Doucet 1984). 